\title{
Capturing and Analyzing Injection Processes with Point of Act System for Improving Quality and Productivity of Health Service Administration
}

\author{
Atsushi Koshio $^{1,2}$ and Masanori Akiyama ${ }^{1,2}$ \\ ${ }^{1}$ Todai Policy Alternatives Research Institute, The Univerisity of Tokyo, Tokyo, Japan \\ ${ }^{2}$ Sloan School of Management, Masachusettus Institute of Techonology, MA, USA \\ \{koshio, makiyama\}@pp.u-tokyo.ac.jp
}

\begin{abstract}
The objective of this paper is to show process data captured with barcode administration system and the results of data analyses and visualizations for improving quality of care and productivity. Hospital Information System named Point-of-Act System that was designed to capture every process of all medical acts was employed to capture data of medical processes. Data of injection process was analyzed based on operative timeliness. The result shows nursing workload didn't be allocated equally through the day and some parts of injections hadn't been administrated at the right time. Improving operative timeliness can contribute to improve quality of care and productivity. This kind of process information has a possibility to provide new research opportunity to analyze outcome with context information including process information.
\end{abstract}

Keywords: Hospital Information System, Process Management, Electrical Data Capturing, Data Analysis, Visualization.

\section{Introduction}

Utilizing data captured and stored by hospital information systems is quite important issue to make hospital IT systems more effective for improving health care quality and productivity. After the report of medication errors and health care quality by Institute of Medicine, these data have been regarded as significant sources for managing hospital environments [1-2]. The data can be constructed as indicators evaluating health care process and outcome. The movements such as "e-indicators" have been trying to analyze and publish these data for the purpose of health outcome management with bench marking and public disclosure [3-11]. Outcome information has a possibility to affect patient's decision and make health care system more patients centered. In addition to this outcome information, process information is also important to understand reality of health care service provision. Process indicators provide context of outcome indicators and show practices to improve quality and productivity [12-15].

Data captured through daily use of hospital information systems are containing data of medication processes. Utilizing process data for understanding daily medication process is an useful way to plan resource allocation in hospitals to 
improve operation and management of service delivery. Process information has an ability to provide why differences of outcome are coming from. And this activities capturing process information and managing medical process also have a possibility to make health care industry more transparent and accountable through publishing the information. Transparency is one of the prioritized areas to be solved to construct better health care systems [16-18].

The objective of this paper is to show process data captured with barcode administration system and the results of analyses and visualizations for achieving the targets described above. This study will emphasize benefits of hospital information system named Point of Act System based on process management and real time data capturing and capturing every activity in the hospitals. In this study, we focus injections and utilize injection process data to analyze medical activities and visualize process in the hospital.

\section{Methods}

\subsection{Things That Need to Be Addressed}

Point of Act System (POAS) is a real time bar-code capturing health information system in International Medical Center of Japan (IMCJ) in Tokyo, Japan [19-22]. POAS has a function to prevent medical errors by certifying correctness of medical activities with capturing bar cords on patients, worker and drugs. It ensure not only the correctness of patients, drug, dose but also route and time based on real time information. At the same time, POAS captures implementation records at each process of medical activities including 6W1H information (When, Where What, Why, for what, to whom and How) of the activities. The basic requirement for successful measurement and data capturing, they must be integrated with the routine provision of care and whenever possible should be done using IS and this system satisfied this requirement [6].

There are basic characteristics of POAS captured data. The data is including every activity in the hospital that means it concludes complete data of the administration. This implies the research based on not sampling data but all data of the medications. The second characteristic is process management of administration. The first target of process management is restraining skipping processes that would sometimes be causes of medication errors. The system record the data at each point of action of processes described by figure 1 showing injection process as an example.

By capturing the data routinely at each process of activities, the data provides information on returned and wasted injections as well as normal injections without entering additional information at end points.

\subsection{Data and Analysis Methods}

Injection process was chose as a target of this study to analyze process data and visualize processes of medical activities. As a standard injection process physicians order for patients and pharmacists pick up and audit the order. These drugs deliver to 


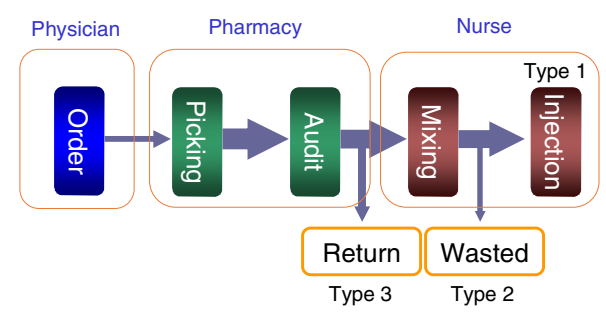

Fig. 1. Data capturing points of Injection processes

nurse stations and nurses mix and inject them to patients. $6 \mathrm{~W} 1 \mathrm{H}$ information have been captured at each point of action; Order, Picking, Audit, Mixing and Injection. In addition to these data, data on order is including "scheduled order time" that shows the scheduled time to inject to patients. These data were liked by serialized ID on each drug and order. Data from July to September 2007 that is including 306768 drugs taken in all injections during the term at every ward in IMCJ was used to analyze. The data was merged from different partial information system such as physician order entry system, pharmacy system and risk management system. Data from other term was also referred if necessary. Basic descriptive analyses and some visualization techniques are applied for analyzing injection process. Especially we described frequency of injection processes minutes by minutes to analyze business of the hospital and time differences including scheduled time and actual administration time to assess time precision of the administration processes to scheduled plan.

\section{Results}

Figure 2 shows the distribution of scheduled injection order time by physicians. Enormous portion of orders were scheduled on 6AM, 10AM and 6PM. Figure 3 shows actual number of activities including mixing of drugs for injections and injections of drugs by minutes. As the peak of order by physicians was 6AM, the time of peak of actual injections is around 6AM. The orders scheduled 6AM were injected

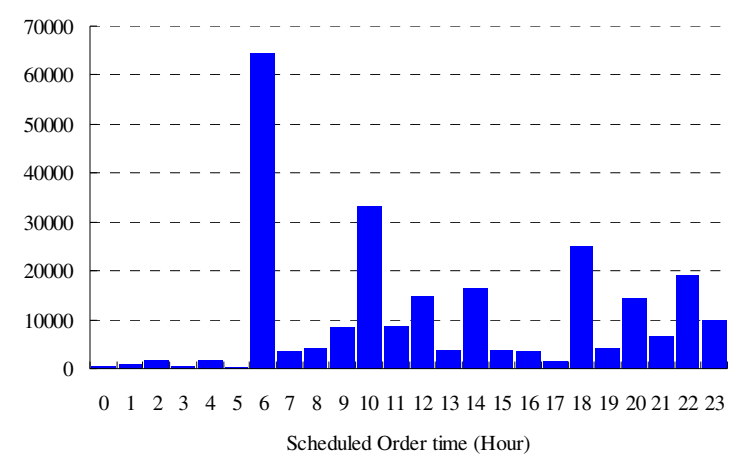

Fig. 2. Distribution of scheduled time 
from around 4AM to 7AM, because the number of orders surpassed capacity of nurses at the time. Nurses adjusted to variation of number of orders by time by injecting earlier than scheduled time.

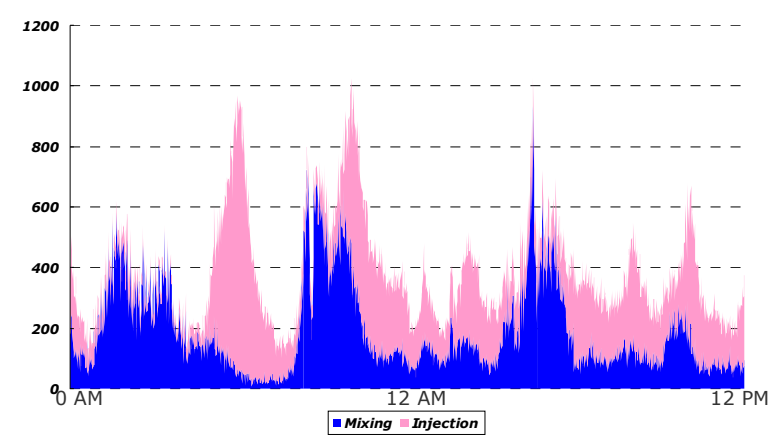

Fig. 3. Distribution of scheduled time of injections

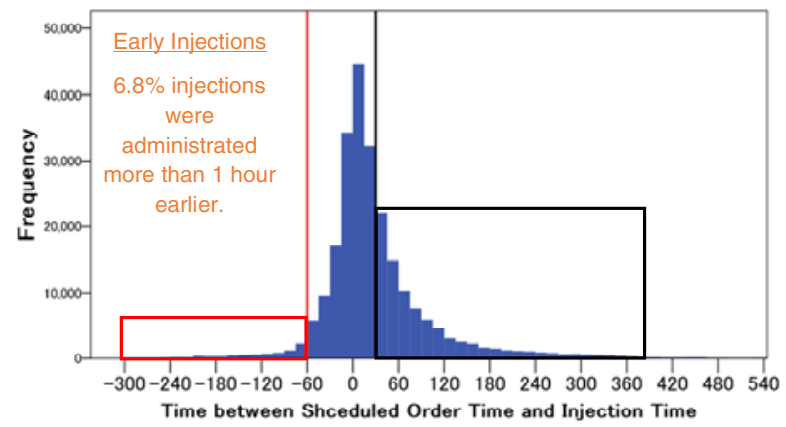

Fig. 4. Distribution of difference between scheduled time and actual time of injections

As described above, nurses adjusted to high frequency of scheduled order by injecting earlier or later. Figure 4 shows Distribution of time difference between scheduled order time and injection time. Time between scheduled order time and injection were calculated by the formula and a minute unit.

(Time between scheduled order time and injection $)=($ Scheduled Order Time $)-$ (Injection Time)

Positive numbers shows early administration of injections, negative number shows lately administration of injections and 0 means right on time. It might be regarded as positive to close to 0 from the point of view of right time administration. Mean of the time is 10.63 minutes. The most frequent category is from 0 to -15 and the second most frequent category is from 15 to 0 . Most of injections are around $0.6 .8 \%$ of injections were regarded as early administration that was defined by one hour early administration[33].

Figure 5 shows time between mixing and scheduled order time. Time between mixing and scheduled order time was calculated by the formula and a minute unit. 


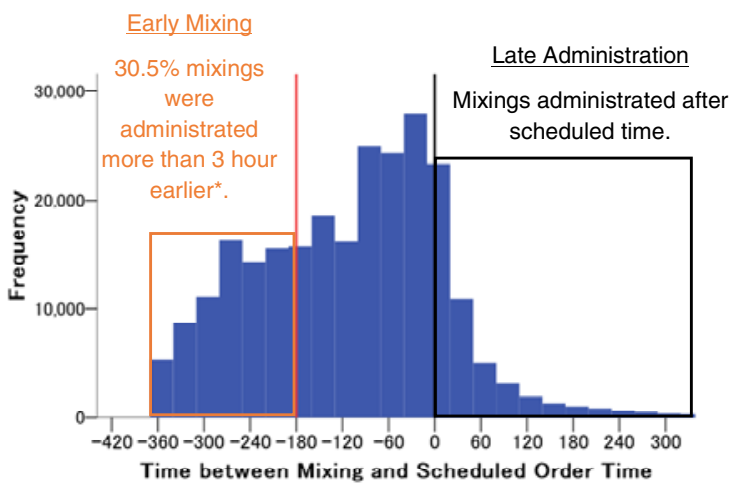

Fig. 5. Distribution of difference between drug mixings and injections

(Time between mixing and scheduled order time $)=($ Mixing time $)-($ Scheduled Order time).

For example, 180 minutes means mixing before 3 hour. Mean of the time is 108.5 minutes. The highest frequency is from 0 to 30 minutes. According the guideline for safe medication in the hospital, drug mixing shouldn't be implemented 3 hours before injection. However, $30.5 \%$ of injections were regarded as early mixing and this information hadn't informed by the nurses.

\section{Discussion}

We captured data by POAS that was designed by the concept of process analysis and management. This concept provided the system a structure to capture the data. According to the survey of system use, the system covered more than $99.9 \%$ mixing drugs and injections. Process management prohibits workers from skipping each activity on the process and that contribute to ensure the correctness of medical activities through the process.

Secondly these process data suggests the importance of process indicator related to outcome indicators. Outcome data and process indicator have been used as measurement indicators of performance. The advantage of outcome indicators is that it explain the achievements of targets itself. Outcome measurement will reflect all aspect of the processes of care and not simply those that are measurable or not [24- 28]. However, as Mant said, difference in outcome might sometimes be due to case mix, how the data were collected, chance, quality of care or other factors such as nutrition, life style. Outcome indicators can be improved if efforts are made to standardize data collection and case mix adjustment systems are developed and validated [7]. Process data can be redeeming indicators to understand meanings of outcome indicators. Process data is providing context information to understand the setting for the case [29-36].

This is the example of research linking process data to some outcome indicators. In this example, we set wasted rate of drugs. If physicians change their order after 


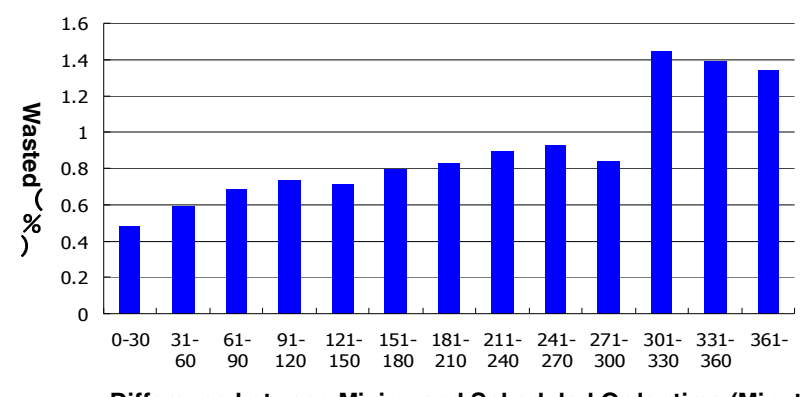

Difference between Mixing and Scheduled Order time (Minute)

Fig. 6. Time difference between drug mixings and injections and drug wasted rate

nurse's mixing drugs, these drugs must be wasted. It is of course necessary to inject right drugs based on up data decisions of physicians, but drug wasting would cause inefficacy of hospital management.

Figure 6 shows the result of analysis that beforehand mixings for laborsaving whose intervals are relatively longer have tend to be wasted by order changes. Analysis on data in unit of wards also shows wards whose intervals between mixing and injection are longer tend to waste more.

Just measuring drug wasted rate is not enough to analyze the cause of high drug wasted rate. By linking process information to outcome information and capturing process routinely, the data make us possible to investigate the reason of some outcomes.

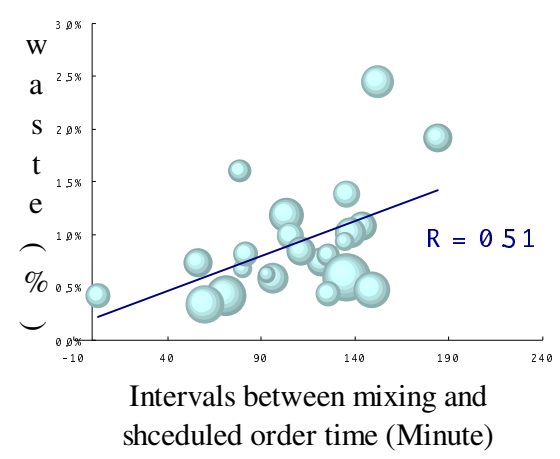

Fig. 7. Relationship between intervals and drug wasted rate

\section{Conclusion}

In this study, we show clearly that data captured by hospital information system provide us new research opportunities to improve quality of care and productivities. Many hospitals have been introducing hospital information system to improve operational efficiency. Secondly use of data captured by HIS hasn't become widely 
yet, though it has a possibility to improve quality and safety of care as well as productivity. The important thing to spread utilization of bust amount of data is providing evidences that secondly use of data can improve them.

Concern on performance measurement has been increasing rapidly and many organization including government and hospital associations and researches have been trying to set indictors for performance measurement [2]. As discussion of process and outcome indicators, both indicators have useful meanings for patients to chose hospitals and acquire healthcare information. This study will help to understand the benefits of process data and contribute to measure quality of care and improve hospital management on health care quality and safety.

\section{References}

1. Institute of Medicine. To error is human. National Academies Press, Washington (1999)

2. Institute of Medicine: Crossing the quality chasm: A New Health System for the 21st Century. National Academies Press, Washington (2001)

3. Fowles, J.B., Kind, E.A., Awwad, S., Weiner, J.P., Chan, K.S.: Performance Measures Using Electronic Health Records: Five Case Studies. The Commonwealth Fund (2008)

4. Baker, D., Persell, S., Thompson, J., Soman, N., Bugner, K., Liss, D., Kmetik, K.: Automated Review of Electorical Health Records to Assess Quality of Care for Outpatients with Heart Failure. Annal of Internal. Medicine (February 2007)

5. Weiner, M., Stump, T.E., Callahan, C.M., Lewis, J.N., McDonald, C.J.: Pursing integration of performance measures into electronic medical records: beta-adrenergic receptor antagonist medications. Qual. Saf. Health Care 14, 99-106 (2005)

6. Bates, D.W., Pappius, E., Kuperman, G.J., Sittig, D., Burstin, H., Fairchild, D., Brennan, T.A., Teich, J.M.: Using information systems to measure and improve quality. International Journal of Medical Informatics 53, 115-124 (1999)

7. Davies, H.T., Marshall, M.N.: Public disclosure of performance data. Lancet 353, 16391640 (1999)

8. Epstein, A.: Rolling down the runway: the challenges ahead for quality report cards. JAMA 279, 1691-1696 (1998)

9. Kassirer, J.P.: The use and abuse of practice profiles. N. Engl. J. Med. 330, 634-635 (1994)

10. Lansky, D.: Overview: performance measures. Comm. J. Qual. Improv. 22, 439-442 (1996)

11. Ådahl, K.: Validation of Transparency in e-Health - Turning Information Visible Through Design. In: The IRIS29 Conference (2006) (Keynote paper)

12. Nelson, R., Ball, M.J.: Consumer Informatics - Applications and Strategies in Cyber Health Care. Springer, New York (2004)

13. Rindebäck, C., Gustavsson, R.: Why Trust is Hard - Challenges in e-Mediated Services. LNCS (LNAI). Springer, Heidelberg (2005)

14. Smith, R.: Transparency: a modern essential. BMJ 328, 7448.0-f (2004)

15. Weinberg, S.L.: Transparency in Medicine: Fact, Fiction, or Mission Impossible?

16. Mant, J.: Process versus outcome indicators in the assessment of quality of health care. International Journal of Quality in Health care 13(6), 475-480 (2001)

17. Marshall, M.N., Shekelle, P.G., Leatherman, S., Brook, R.H.: The Publication of Performance Data in Health Care. Nuffield Trust, London (2000)

18. Becker, J., Kugeler, M., Rosemann, M. (eds.): Process Management: A Guide for the Design of Business Processes, 2nd edn. Springer, Berlin (2007) 
19. Akiyama, M., Kondo, T.: Risk Management and Measuring Productivity with POAS Point of Act System. Medinfo., 208-212 (2007)

20. Akiyama, M.: Migration of the Japanese Healthcare Enterprise from a Financial to Integrated Management: Strategy and Architecture. Medinfo., 715-718 (2001)

21. Akiyama, M.: Risk Management and Measuring Productivity with POAS- Point of Act System. Methods inf. Med. 46, 686-693 (2007)

22. Akiyama, M.: A Medical Information System as ERP (Enterprise Resource Planning) for the Hospital Management. Medinfo. 11, 1502 (2004)

23. Westphal, C., Blaxton, T.: The process of discovery begins by getting an overall picture of the available data Data Mining Solutions - Methods and Tools for Solving Real-World Problems. John Wiley \& Sons, New York (1998)

24. Noon, C.E., Hankins, C.T.: Spatial Data Visualization in Healthcare: Supporting a Facility Location Decision via GIS-based Market Analysis. In: Proceedings of the 34th Hawaii International Conference on System Sciences (2001)

25. Ammenwerth, E., Ehlers, F., Eichstädter, R., Haux, R., Kruppa, B., Parzer, P., et al.: Analysis and modeling of the treatment process characterizing the cooperation within multiprofessional treatment teams. In: Hasman, A., Blobel, B., Dudeck, J., Engelbrecht, R., Gell, G., Prokosch, H.U. (eds.) Proceedings of the MIE 2000, pp. 57-61. IOS Press, Amsterdam (2000)

26. Fung, A., Graham, M., Weil, D., Fagotto, E.: Transparency Policies: Two Possible Futures. Taubman Center Policy Briefs (May 2007)

27. McNaughton, H., McPherson, K., Taylor, W., Weatherall, M.: FRACP. Relationship Between Process and Outcome in Stroke Care

28. Mant, J., Hicks, N.: Detecting differences in quality of care: the sensitivity of measures of process and outcome in treating acute myocardial infarction. BMJ 311, 793-796 (1995)

29. Mant, J., Hicks, N.R., Fletcher, J.: Correcting outcome data for case mix in stroke medicine: study should have had more patients or longer time scale. BMJ 313, 1006 (1996)

30. Davies, H.T., Lampel, J.: Trust in performance indicators. Qual. Health Care 7, 159-162 (1998)

31. Thomson, R., Lally, J.: Clinical indicators. Qual. Health Care 7, 122 (1998)

32. Staccini, P., Joubert, M., Quaranta, J.-F., Fieschi, D., Fieschi, M.: Modelling health care processes for eliciting user requirements: a way to link a quality paradigm and clinical information system design. International Journal of Medical Informatics 64, 129-142 (2001)

33. Sakowski, J., Leonard, T., Colburn, S., Michaelsen, B., Schiro, T., Schneider, J., Newman, J.M.: Using a Bar-Coded Medication Administration System to Prevent Medication Errors. American Journal of Health-System Pharmacy 62(24), 2619-2625 (2005)

34. Ammenwerth, E., Ehlers, F., Eichst'adter, R., Haux, R., Kruppa, B., Parzer, P., et al.: Analysis and modeling of the treatment process characterizing the cooperation within multiprofessional treatment teams. In: Hasman, A., Blobel, B., Dudeck, J., Engelbrecht, R., Gell, G., Prokosch, H.U. (eds.) Proceedings of the MIE 2000, pp. 57-61. IOS Press, Amsterdam (2000)

35. Lenz, R., Reichert, M.: IT Support for Healthcare Processes. In: van der Aalst, W.M.P., Benatallah, B., Casati, F., Curbera, F. (eds.) BPM 2005. LNCS, vol. 3649, pp. 354-363. Springer, Heidelberg (2005)

36. Plsek, P.E.: Systematic design of healthcare processes. Qual. Health Care 6, 40-48 (1997)

37. Kueng, P., Kawalek, P.: Goal-based business process models: creation and evaluation. Business Process Manage. J. 3, 17-38 (1997)

38. Dadam, P., Reichert, M.: Towards a new dimension in clinical information processing. Stud. Health Technol. Inform. 77, 295-301 (2000) 